\title{
The method of calculating emissions of pollutants from road transport in an urban environment
}

\author{
I. A. Teterina ${ }^{1, *}$ and E. V. Parsaev ${ }^{1}$ \\ ${ }^{1}$ Dept. of Scientific Research Siberian State Automobile and Highway University (SibADI), 644080, \\ Omsk, Mira Ave., 5, Russia
}

\begin{abstract}
To assess the quality of road traffic organization on environmental indicators, two methods of five regulations operating in the Russian Federation, which take into account the parameters of traffic flow, affecting the volume of emissions Pollutants. The parameter that affects the results of calculations in both methods is the average speed of movement. In real-world conditions on urban highways there are areas where the traffic flow is uneven (braking, acceleration, stopping), which entails an increase in the amount of pollutants from vehicles. At the same time, this uneven traffic is largely due to the existing the road design and traffic engineering on certain elements of the road network. This is the basis for the development of a methodology for calculating pollutant emissions to assess the quality of the traffic engineering, taking into account the uneven flow of traffic.
\end{abstract}

\section{Introduction}

In accordance with Decree of the Government of the Russian Federation dated December 25, 2015 No. 1440 "On the approval of requirements for programs for the integrated development of the transport infrastructure of settlements, urban districts," the program for the comprehensive development of the city's transport infrastructure should include: assessing the level of negative impact of the transport infrastructure on the environment, safety and public health; measures to reduce the negative impact of transport on the environment and public health. In addition, according to the Order of the Ministry of Transport of the Russian Federation dated March 17, 2015 No. 43 "On approval of the Rules for the preparation of projects and schemes road design and traffic engineering”, the developed measures for the road design and traffic engineering (RDTE) should constitute an integrated system of technically, economically and environmentally sound measures of an organizational nature, and one of the tasks of developing project documentation for RDTE is to reduce the negative impact of road transport on the environment. The most harmful impact on the part of transport infrastructure in large cities is caused by air pollution by automobiles $[1,2]$. Therefore, to solve the above problems, a technique is

\footnotetext{
* Corresponding author: Iateterina@mail.ru
} 
needed that allows not only an environmental assessment of the quality of the existing traffic organization, but also calculations to analyze various options for design decisions on the elements of the road and street network (RSN) of settlements.

There are two types of methods that assess the level of air pollution by traffic: methods that estimate the concentration of pollutants in the roadside territory $[1,3,4,5]$ and methods that estimate the amount of pollutant emissions by automobile road [1,2,6,7,8,9]. The methods of the first type are focused on assessing the quality of atmospheric air, in which pollutants can be present not only from the exhaust gases of vehicles, but also emissions from stationary sources [10], therefore, their use for assessing the quality of RDTE on RSN elements in settlements is limited and can be used for certain conditions. Therefore, methods of the second type are more suitable for environmental assessment of the quality of RDTE.

Currently, five regulatory documents regulating the implementation of pollutant emissions calculations by road transport are legally binding in Russia: four methods, according to the list of [11] and GOST P56162-2014.

Moreover, the methodology[6] and GOST R 56162 - 2014 practically repeat each other.

To assess the quality of RDTE by environmental indicators, the most interesting are the methods [6,7], which take into account the parameters of the traffic flows that affect the volume of pollutant emissions. Both methods have a similar approach to calculating emissions of pollutants from moving vehicles, an important parameter influencing the results of calculations is the average speed of movement.

But average speed can be used to indirectly evaluate the effectiveness of RDTE. In real conditions, there are areas on city highways where traffic flows unevenly (braking, accelerating, stopping), which entails an increase in the amount of pollutant emissions from vehicles. At the same time, this uneven movement is largely due to the existing RDTE on certain elements of the RSN.

\section{Task assignment}

The above was the basis for the development of a methodology for calculating pollutant emissions from non-stationary traffic flows, taking into account their unevenness. The subject of research, in this case, will be the dependencies connecting the amount of pollutant emissions from traffic flows regimes.

\section{Theory}

The main source of pollutant emissions in traffic is vehicle engines.

To evaluate automobile engines as a source of pollution, indicators are used that take into account the chemical composition and amount of exhaust gases, as well as energy indicators of vehicles in specific or averaged operating conditions [1].

The intensity of emissions of the i-th pollutant emitted by the engine per unit time $(\mathrm{g} / \mathrm{h})$ depends on the concentration of the i-th pollutant in the exhaust gases $\mathrm{Ci}$ and volumetric exhaust emissions $Q v[1]$ :

$$
G_{i}=C_{i} \cdot Q_{v}
$$

where $C i$ is the concentration of the i-th pollutant, $\mathrm{g} / \mathrm{m}^{3} ; \mathrm{Qv}$ volumetric exhaust emissions, $\mathrm{m}^{3} / \mathrm{h}$.

The calculation of the amount of harmful emissions emitted by the transport stream according to the methods [6,7] is based on the generally accepted indicator $m_{p i}-$ the 
emission of the i-th pollutant by one car per unit of distance traveled $(\mathrm{g} / \mathrm{km})$, which is called mileage emission [1]:

$$
m_{p i}=G_{i} / V
$$

where $V$ - is the speed of the car, $\mathrm{km} / \mathrm{h}$.

The mass emission $M_{L i}$ of the i-th pollutant by cars of the same type, the number of which is $N$, will be $N$ times greater:

$$
M_{L i}=m_{L i} \cdot N=m_{\mathrm{pi}} \cdot l \cdot N .
$$

where $l$ - road length (or its section), $\mathrm{km} ; m_{\mathrm{Li}}$ - mileage release of a pollutant by one vehicle.

The intensity of traffic flow $\lambda$ (avt./h) is determined by the ratio of the number of $N$ cars to the $T$ time interval (hour): $\lambda=N / T$. Then the mass emission $m_{L i}$ (g) i-th pollutant by traffic flow can be associated with the intensity of traffic and the length of road:

$$
M_{L i}=m_{L i} \cdot \lambda \cdot T=m_{\mathrm{pi}} \cdot l \cdot \lambda \cdot T .
$$

Usually in the traffic flow moving vehicles of different types.

They are equipped with various engines. To account for the types of vehicles moving in the stream, apply the well-known formula $[2,6,7]$ in one form or another:

$$
M_{h L i}=\sum_{k=1}^{n} m_{\mathrm{pik}} \cdot l_{k} \cdot \lambda_{k},
$$

where $\mathrm{m}_{\text {pik }}$ - mileage emission of the i-th pollution by a vehicle of type $k ; n$ - number of types of vehicles $k=1,2, \ldots, n ; I_{k}$ - length of the section of the highway traveled by a vehicle of type $k ; \lambda_{k}$ - traffic intensity of type $k$ vehicles on the highway section.

In this form, the formula (5) takes into account the movement of vehicles of different types on different lanes. The current methods apply different criteria for splitting vehicles into types. The approach to pollutant emissions of used in the methods [6,7] is fair for the stationary mode of traffic flow.

It is known that the movement of vehicles in urban environments is usually nonstationary [1]. Cars move in modes of acceleration and slowdown. In the dispersal mode, emissions of pollutants are increasing, and in the mode of deceleration - decrease [1].

In this paper, it is proposed in the calculations of pollutant emissions from traffic flows to take into account the average speed in those sections of the highway where the flow is stationary, and on the elements of the highway where the flow is unsteady to take into account additional emissions. The additional emission of pollutants from the traffic stream should be considered separately in the cases: if the cars stopped (there are deceleration modes, idle and acceleration), and the situation when the cars are delayed but not stopped (deceleration and acceleration).

The main effect on both fuel consumption and emissions of toxic substances is exerted by the acceleration mode. To take into account the effect of acceleration and deceleration rates on automobile emissions of pollutants, it is proposed to use correction factors: 


$$
k_{\mathrm{r}}=m_{\mathrm{prvi}} / m_{\mathrm{pvi}}
$$

where $k_{r}$ - coefficient taking into account the effect of acceleration intensity on the emission of pollutants; $m_{\text {prvi }}$ - mileage emission of the i-th pollutant in acceleration mode to a speed $V ; m_{p v i}$ - mileage emission of the i-th pollutant when the vehicle is moving at a speed $V$;

$$
k_{\mathrm{z}}=m_{\mathrm{pzvi}} / m_{\mathrm{p} v i}
$$

where $k_{z}$ - coefficient taking into account the effect of the intensity of deceleration on the emission of pollutants; $m_{\text {prvi }}$ - mileage emission of the i-th pollutant in deceleration mode from speed $V$ to a stop.

Table 1 shows the known values $k_{r}, k_{z}$ of the coefficients $k_{r}, k_{z}$ for different modes of movement of vehicles with gasoline and diesel engines according to the work [2].

Table 1. the values of coefficients for different types of vehicles during acceleration $\left(k_{r}\right)$ and

\begin{tabular}{|c|c|c|c|c|c|c|c|c|c|}
\hline \multirow{2}{*}{$\begin{array}{c}\text { Accele } \\
\text { ration } \\
\text { (slowd } \\
\text { own) } \\
\text { to }\end{array}$} & \multirow[b]{2}{*}{$\begin{array}{l}\text { type } \\
\text { of car }\end{array}$} & \multicolumn{4}{|c|}{$k_{r}$} & \multicolumn{4}{|c|}{$k_{z}$} \\
\hline & & $\mathrm{CO}$ & $\mathbf{C}_{\mathrm{x}} \mathbf{H}_{\mathrm{y}}$ & $\mathrm{NO}_{\mathrm{x}}$ & $\begin{array}{c}\text { particl } \\
\text { es }\end{array}$ & $\mathrm{CO}$ & $\mathrm{C}_{\mathrm{x}} \mathrm{H}_{\mathrm{y}}$ & $\mathrm{NO}_{\mathrm{x}}$ & $\begin{array}{c}\text { particle } \\
\text { s }\end{array}$ \\
\hline \multirow{3}{*}{$\begin{array}{c}20 \\
\mathrm{~km} / \mathrm{h}\end{array}$} & BM1 & $\begin{array}{c}13, \\
1\end{array}$ & 5,2 & 13,2 & - & 0,3 & 0,3 & 0,1 & - \\
\hline & BM3 & $\begin{array}{c}16, \\
9\end{array}$ & 5,6 & 6,3 & - & 0,2 & 0,3 & 0,04 & - \\
\hline & DM3 & 1,3 & 1,5 & 5,6 & 18,2 & 0,2 & 0,2 & 0,1 & 0,22 \\
\hline \multirow{3}{*}{$\begin{array}{c}60 \\
\mathrm{~km} / \mathrm{h}\end{array}$} & BM1 & $\begin{array}{c}17 \\
8\end{array}$ & 3,7 & 6,0 & - & 0,06 & 0,05 & 0,01 & - \\
\hline & BM3 & 6,5 & 2,9 & 0,7 & - & 0,08 & 0,16 & 0,01 & - \\
\hline & DM3 & 1,3 & 0,7 & 1,3 & 6,2 & 0,09 & 0,03 & 0,01 & 0,02 \\
\hline
\end{tabular}
deceleration $\left(k_{z}\right)$

To account for the modes of movement, it is proposed to calculate the mass emission of pollutants according to formulas (8) and (9):

$$
\begin{aligned}
& m_{L r i}=m_{\mathrm{pri}} \cdot l_{\mathrm{r}}=k_{r} \cdot m_{\mathrm{pi}} \cdot l_{\mathrm{r}}, \\
& m_{L_{\mathrm{z} i}}=m_{\mathrm{pzi}} \cdot l_{\mathrm{z}}=k_{\mathrm{z}} \cdot m_{\mathrm{pi}} \cdot l_{\mathrm{z}} .
\end{aligned}
$$

It is proposed to calculate the length of the highway section on which the vehicle accelerates and brakes using the formulas:

$$
\begin{aligned}
& l_{\mathrm{r}}=\frac{V^{2}}{2 \cdot a}, \\
& l_{\mathrm{z}}=\frac{V^{2}}{2 \cdot j},
\end{aligned}
$$


where $j$ - slowing down traffic, $\mathrm{m} / \mathrm{s}^{2}$.

To perform the calculations, the numerical value of acceleration and deceleration is proposed to be taken on the basis of service modes, and not emergency ( $a=1.5 \mathrm{~m} / \mathrm{s}^{2}, j=$ $2.5 \mathrm{~m} / \mathrm{s}^{2}$ ) [12].

An additional emission of pollutants associated with a stop is present primarily on elements of city highways with traffic lights (for example, an adjustable pedestrian crossing). In this case, the stopping time and interruption frequency depend not only on the structure of the traffic light control cycle, but also on the operation mode of the traffic light object $[13,14,15]$.

The additional emission of i-th pollutant (g) by one vehicle during a stop time, taking into account formula (1), can be calculated by the formula:

$$
d_{i}=C_{i} \cdot Q_{\mathrm{g}} \cdot \mathrm{t}_{\mathrm{xx}}
$$

The conditional exhaust gas flow according to [2] is determined by:

$$
Q_{\mathrm{g}}=\frac{i \cdot V_{h} \cdot n}{30 \cdot \tau},
$$

where $i$ - number of cylinders; $V_{h}$ - cylinder displacement, $1 ; n$ - crankshaft rotation speed, rpm.; $\tau$ - engine cycle ( 2 or 4 ).

The concentration of $\mathrm{i}$-th pollutant $\mathrm{Ci}$ in the exhaust gases depends on the type of fuel and is currently standardized for vehicles on carbon monoxide for gasoline and soot for diesel.

In accordance with the methods of [6,7] the additional emission is calculated by the formula:

$$
d_{i}=m_{\mathrm{xx} i} \cdot \mathrm{t}_{\mathrm{xx}}
$$

$m_{x x i}-$ specific emission of the i-th pollutant when the engine is idling, $\mathrm{g} / \mathrm{min}$.

For an objective assessment of the quality of RDTE on a section of the city highway according to environmental indicators, it is proposed to carry out calculations according to the recommendations of HCM [16], namely, excluding the service level F (level of service (LOS) F), at which the flows are unstable or traffic delays are long $[17,18,19,20]$.

\section{Research}

To compare the results of calculations of emissions of pollutants from one car driving in compliance with the rules of the road according to the proposed methodology and GOST, a section of a city highway $1 \mathrm{~km}$ long was simulated, in which there are nine sections shown in Figure 1. The characteristic of movement in sections: 1 - acceleration mode from a stop line to a set constant speed of $60 \mathrm{~km} / \mathrm{h} ; 2$ - movement at a constant speed of $60 \mathrm{~km} / \mathrm{h} ; 3$ deceleration to a stop; 4 - acceleration to a speed of $20 \mathrm{~km} / \mathrm{h} ; 5$ - movement at a constant speed of $20 \mathrm{~km} / \mathrm{h} ; 6$ - deceleration to a stop, s stopping time $15 \mathrm{~s} ; 7$ - acceleration to a speed of $60 \mathrm{~km} / \mathrm{h} ; 8$ - movement at a constant speed of $60 \mathrm{~km} / \mathrm{h} ; 9$ - deceleration to a stop at the stop line.

The average speed of the car in this section was $8.22 \mathrm{~m} / \mathrm{s}$ (about $30 \mathrm{~km} / \mathrm{h}$ ). 


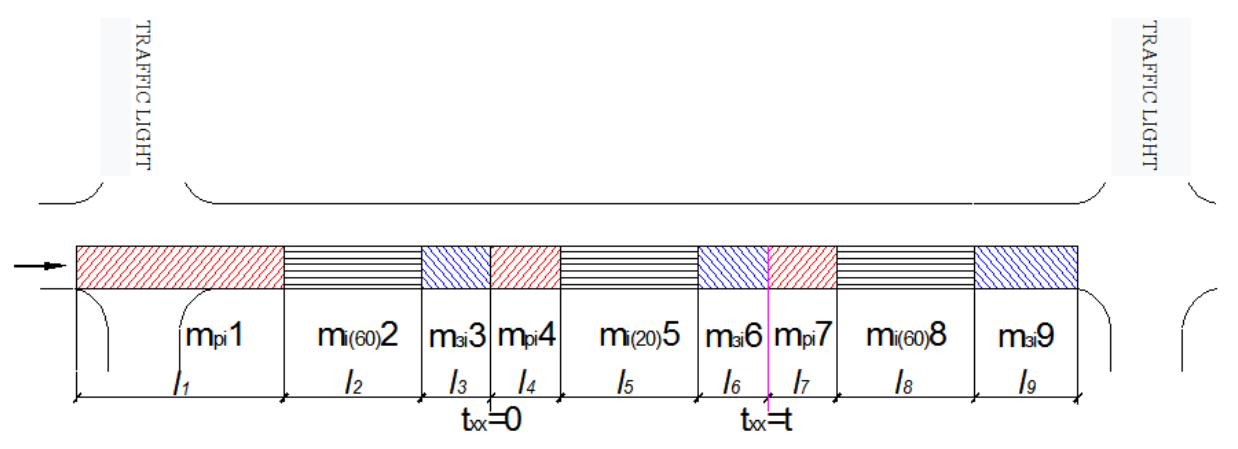

Fig. 1. Design scheme of highway section (segment)

Table 2. Original data and results of calculations of emissions of carbon monoxide (CO) one car on the section of the line (segment) a length of $1 \mathrm{~km}$

\begin{tabular}{|c|c|c|c|c|c|c|c|c|c|c|}
\hline \multirow{2}{*}{$\begin{array}{c}\text { Option } \\
T, \mathrm{~s}\end{array}$} & \multicolumn{10}{|c|}{ Numbered values } \\
\hline & 11 & 15 & 7 & 4 & 36 & 2 & 15 & 11 & 14 & 7 \\
\hline$t_{\mathrm{xx}}, \min$. & 0 & 0 & 0 & 0 & 0 & 0 & $\begin{array}{c}0,2 \\
5\end{array}$ & 0 & 0 & 0 \\
\hline $\begin{array}{l}m_{\mathrm{xxCO}} \\
\mathrm{g} / \mathrm{min}\end{array}$ & 0 & 0 & & 0 & 0 & 0 & 0,5 & 0 & 0 & 0 \\
\hline$a, \mathrm{~m} / \mathrm{s}^{2}$ & 1,5 & 0 & 0 & 1,5 & 0 & 0 & 0 & 1,5 & 0 & 0 \\
\hline$j, \mathrm{~m} / \mathrm{s}^{2}$ & 0 & 0 & 2,5 & 0 & 0 & 2,5 & 0 & 0 & 0 & 2,5 \\
\hline$V, \mathrm{~m} / \mathrm{s}$ & 0 & 16,7 & 0 & 0 & 5,6 & 0 & 0 & 0 & 16,7 & 0 \\
\hline$k_{\mathrm{z}}$ & 0 & 0 & 0,06 & 0 & 0 & 0,3 & 0 & 0 & 0 & 0,06 \\
\hline$k_{\mathrm{r}}$ & 17,8 & 0 & 0 & 13,1 & 0 & 0 & 0 & 17,8 & 0 & 0 \\
\hline$l_{z}, \mathrm{~m}$ & 0 & 0 & 55,58 & 0 & 0 & 6,18 & 0 & 0 & 0 & 55,58 \\
\hline$l_{\mathrm{r}}, \mathrm{m}$ & 92,63 & 0 & 0 & 10,30 & 0 & 0 & 0 & 92,63 & 0 & 0 \\
\hline$l, \mathrm{~m}$ & 0 & 250 & 0 & 0 & 200 & 0 & 0 & 0 & 237 & 0 \\
\hline $\begin{array}{c}M_{\mathrm{pzCO}}, \\
\mathrm{g} / \mathrm{km}\end{array}$ & 0 & 0 & 0,063 & 0 & 0 & 1,26 & 0 & 0 & 0 & 0,063 \\
\hline $\begin{array}{c}M_{\mathrm{prCO}} \\
\mathrm{g} / \mathrm{km}\end{array}$ & 18,69 & 0 & 0 & 55,02 & 0 & 0 & 0 & 18,69 & 0 & 0 \\
\hline $\begin{array}{l}M_{\mathrm{pCO}}, \\
\mathrm{g} / \mathrm{km}\end{array}$ & 0 & 1,05 & 0 & 0 & 4,2 & 0 & 0 & 0 & 1,05 & 0 \\
\hline $\begin{array}{l}\text { highway } \\
\text { section }\end{array}$ & $\begin{array}{c}\mathrm{m}_{\text {Lpco_- }} \\
1\end{array}$ & $\begin{array}{c}\mathrm{m}_{\text {Lco }} \\
(60)_{-} \\
2 \\
\end{array}$ & $\begin{array}{c}\mathrm{m}_{\text {Lзсо_- }} \\
3\end{array}$ & $\begin{array}{c}\mathrm{m}_{\text {Lpco_- }} \\
4\end{array}$ & $\begin{array}{c}\mathrm{m}_{\mathrm{Lco}} \\
(20)_{-} \\
5 \\
\end{array}$ & $\begin{array}{c}\mathrm{m}_{\text {Lsco- }} \\
6\end{array}$ & $\begin{array}{c}\mathrm{d}_{\mathrm{co}} \\
- \\
\end{array}$ & $\begin{array}{c}\mathrm{m}_{\text {Lpco_- }} \\
7\end{array}$ & $\begin{array}{c}\mathrm{m}_{\mathrm{Lco}} \\
(60)_{-} \\
8 \\
\end{array}$ & $\begin{array}{c}\mathrm{m}_{\mathrm{Lzco}}- \\
9\end{array}$ \\
\hline $\begin{array}{l}\text { pollutant } \\
\text { emission } \\
\text { s CO, g }\end{array}$ & 1,73 & 0,26 & 0,004 & 0,567 & 0,84 & 0,008 & $\begin{array}{c}0,1 \\
2\end{array}$ & 1,73 & 0,25 & 0,004 \\
\hline
\end{tabular}




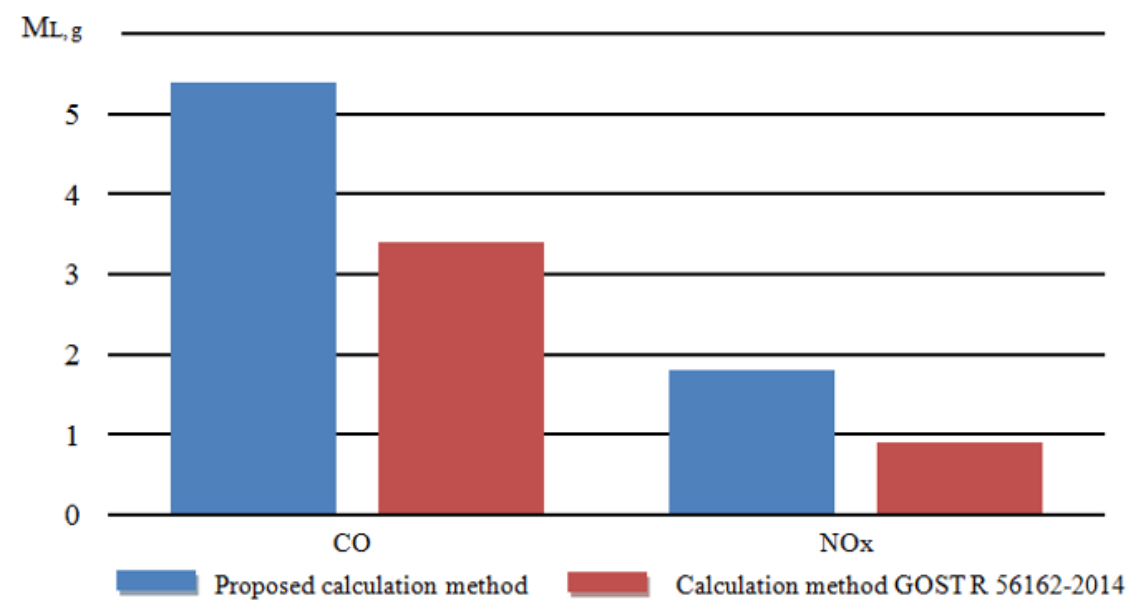

Fig. 2. Total mass emission of pollutants by one car when driving on a simulated section of the 1 km long highway

\section{Conclusion}

The total mass emission of pollutants on a simulated section of the highway by one passenger car for carbon monoxide (CO) and nitrogen oxides (NOx), calculated according to the GOST [6] method and the proposed method is presented in Figure 2. The same figure shows the emission values of the same HV when one car is moving on the reference area (movement at a constant speed of $60 \mathrm{~km} / \mathrm{h}$ ). The difference in the results of carbon monoxide emissions according to the proposed GOST methodology was $57 \%$ and the nitrogen oxide emissions of $94 \%$.

\section{References}

1. A.B. Dyakov, Yu.V. Ignatiev and E.P Konshin, Ecological safety of traffic flows (Transport, 1989)

2. V.V. Donchenko, Yu.I. Kunin, A.V. Ruzsky and V. Vizhensky, Methods for calculating emissions from vehicles and the results of their application, Journal of Automotive Engineers. v. 3(86), pp. 44-51 (2014)

3. L. Zheng, C. Zhu, N. Zhu, T. He, N. Dong, H. Huang, Feature selection-based approach for urban short-term travel speed prediction, IET Intelligent Transport Systems. v. 12(6), pp. 474-484 (2018)

4. V.S. Volkov and E.V. Tarasova, Monitoring of the urban environment, taking into account the activities of road transport, Modern problems of science and education, 2, (2014)

5. R.A. Korablev, E.V. Tarasova, V.P. Belokurov, and P.V. Meshcheryakov, The calculation of the concentration of pollutant emissions by road in the city of Voronezh, Alternative energy sources in the transport and technological complex: problems and prospects of rational use, 2(1), pp. 210-213 (2015)

6. Methodology for determining emissions of vehicles for carrying out summary calculations of urban air pollution (Research Institute Atmosphere, 2010) 
7. Methodology for calculating atmospheric emissions of pollutants by road on urban highways (NIIAT, 1997)

8. A.Yu. Marmilov, A.N. Kudryavtsev, V.D. Aldoshin and N.A. Muravyova Ecological examination of the determination of emissions of harmful substances into the air from motor flows, Alternative energy sources in the transport and technological complex: problems and prospects of rational use, v. 3(2). pp. 332-336 (2016)

9. E.V. Tarasova, V.S. Volkov, Calculation of the total emission of pollutants depending on the distance from the road, Alternative energy sources in the transport and technological complex: problems and prospects of rational use. 1. pp. 291-293 (2014)

10. I.F. Suleymanov, E.V. Bondarenko, A.A. Filippov and A.M. Fedotov, Features of the organization of car traffic according to environmental criteria, Bulletin of Irkutsk State Technical University. v. 21. 6. pp. 149-158 (2017)

11. The list of methods used in 2018 to calculate, standardize and control emissions of pollutants into the air, (JSC "Research Institute of Atmospheric Air Protection", 2017)

12. V.D. Balakin and I.V. Shchipan, Reconstruction of the mechanism of a traffic accident with a collision of cars, Bulletin of the Siberian State Automobile and Highway Academy. 2(36). pp. 7-12 (2014)

13. Y Ryabokon, The Method of Determining the Number of Phases in the Traffic Light Cycle on the Allowable Intensity of Conflicting Flows, Transportation Research Procedia, 20, pp. 571-577 (2017)

14. A. Kashtalinsky, V. Petrov and Y. Ryabokon, Method Considering Traffic Stream Variability over Time when Determining Multiprogram Control Modes at Signaled Intersections. Transportation Research Procedia, 20, pp. 277-282 (2017)

15. J. Beaudoin, Y.H. Farzin and L. Lawell, Public transit investment and sustainable transportation: A review of studies of transit's impact on traffic congestion and air quality, Research in Transportation Economics, 52, pp. 15-22 (2015)

16. Highway Capacity Manual (TRB, Washington, DC, 2000)

17. A. Bourliva, N. Kantiranis, L. Papadopoulou, E. Aidona, C. Christophoridis, P. Kollias, M. Evgenakis and K. Fytianos, Seasonal and spatial variations of magnetic susceptibility and potentially toxic elements (PTEs) in road dusts of Thessaloniki city, Greece: A one-year monitoring period, Science of the Total Environment. 639, pp. 417-427 (2018)

18. X. Hao, X. Zhang, X. Cao, X. Shen, J. Shi, Z. Yao, Characterization and carcinogenic risk assessment of polycyclic aromatic and nitro-polycyclic aromatic hydrocarbons in exhaust emission from gasoline passenger cars using on-road measurements in Beijing, Chin Science of the Total Environment, 645, pp. 347-355 (2018)

19. S.M. Hatefi, Strategic planning of urban transportation system based on sustainable development dimensions using an integrated SWOT and fuzzy COPRAS approach. Global Journal of Environmental Science and Management, 4(1), pp. 99-112 (2018)

20. L. Dimitriou, D. Efthymiou, C. Antoniou, Saving lives through faster emergency unit response times: Role of accessibility and environmental factors. Journal of Transportation Engineering. Part A: Systems. 144(9), № 04018053, (2018) 